\title{
Fedra, a cintilante
}

\author{
Graça Abreu
}

\begin{abstract}
Jean Racine, Fedra, transcriação em versos dodecassílabos portugueses, posfácio e notas por António Barahona, Porto, Porto Editora, Biblioteca Sudoeste, 2003, 175 pp.
\end{abstract}

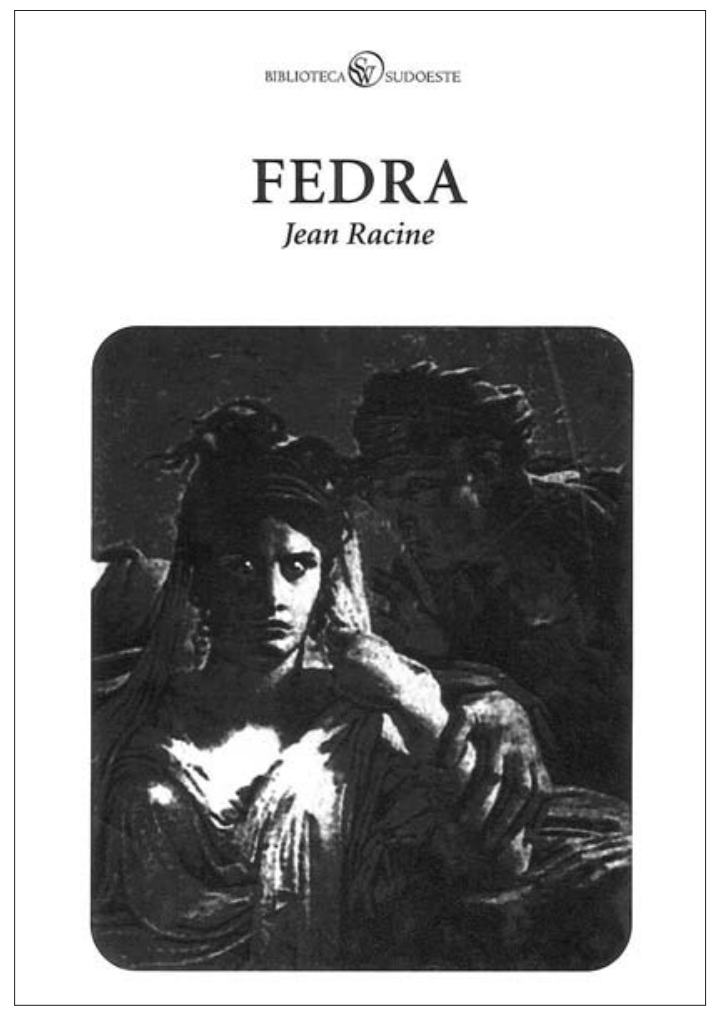

A má fortuna dos clássicos em Portugal, e nomeadamente dos autores de teatro do chamado classicismo francês, visivel na escassez de traduções produzidas durante as últimas décadas, leva ao regozijo de todo e qualquer amador ou especialista da época, de cada vez que alguém ousa empreender a nada fácil tarefa de verter para português textos cuja língua falada, já distante da portuguesa aquando criados, dela se encontram hoje ainda mais afastados. E ao dizer língua falada, a intencionalidade desta minha expressão leva em conta não só que todo o texto de teatro se destina, em primeiro lugar, a uma oralidade específica - a da sua proferição em cena mas também que, por razões que excedem o âmbito do que aqui me compete analisar, no tempo de Racine (visto dele se tratar) nunca um texto era publicado antes de representado e mais: a publicação só se fazia após a última representação, da série que sucedia à estreia.

Pode a virtuosidade da composição raciniana enganarnos, sobretudo em Phédre, obra-prima de harmonia e equilibrio em que a intensidade e a força das paixões se acentuam pela contenção do estilo, e levar-nos a supor ser fundamentalmente à leitura que se destina tão rigoroso trabalho de ecos, retomas e contrapontos rítmica e melodicamente dispostos ao longo de todo o texto, em arquitectura precisa e minuciosa, de que o exemplo maior é dado pelo anúncio de regresso de Teseu exactamente a meio da peça ("Le roi, qu'on a cru mort, va paraître à vos yeux", v. 827; a peça tem 1654 versos), sem prejuizo do crescendo patético e, antes pelo contrário, reforçando-o, no espectador (ou leitor) assim conduzido, em justa medida concertante (a tão prezada mediocritas clássica) a um cúmulo emocional. Porém, se só a leitura permite esta percepção racional dos pormenores de composição, só a situação de espectador (ouvindo e vendo) proporciona a fruição plena dos efeitos daquilo que a frieza da análise pode reduzir a processos de escrita, ainda que um excesso (o que sempre a poesia tem a mais em relação a meros processos e por onde se insinuam sentido e prazer), o da perfeição poética, resista, irredutível à decomposição analítica.

Ora, sabidas as razões por que o texto era o que os autores mais cuidavam neste período (as difíceis condições de representação, em particular a má visibilidade, implicavam a total captação da atenção e do envolvimento do público pelo discurso), sendo as outras práticas abrangidas na arte teatral muito menos trabalhadas, vários aspectos da encantatória escrita de Racine (exemplo máximo mas não único) podem ser vistos a nova luz: a utilização dos dísticos de alexandrinos (o alexandrino era inalienável na tragédia e a as regras cumpriam-se) torna mais fácil o

acompanhamento auditivo e a adesão do espectador pela dupla cadência criada - cesuras e versos rimados (meio de obstar a que à deficiente acústica das salas se juntasse o ruído de um público distraído e agitado); a simplicidade da linguagem actua no mesmo sentido de uma fácil captação (o estudo do léxico de Racine comprova ser pouco vasto); o uso de lugares-comuns estilísticos e imagísticos (sobretudo metáforas) permite compreensão imediata mesmo que não total (sobretudo quando o autor joga na ambivalência de sentidos, entre o metafórico fixado e o literal).

Sendo, pois, com esta pobreza de materiais que Racine constrói o brilhante edifício da sua dramaturgia, vejamos o que se passa na tradução (a que o autor prefere chamar transcriação) de António Barahona.

Detenho-me em primeiro lugar nesta palavra transcriação - que AB procura não exactamente explicar mas, de algum modo, iluminar, por sucessivas aproximações 
ao seu trabalho de transcriador, no Posfácio (pp. 139-155), de que transcrevo alguns passos:

Transcriar um texto é aprofundá-lo e, depois, esquecê-lo para reencontrálo à superficie da pele, reescrito numa tatuagem. / Transcriar uma tragédia de Racine e especialmente Fedra é, além disso, usar o fôlego e a voz, e o corpo todo feito uma caixa de ressonância. [...] A versão final da transcriação só termina quando se pode ler o texto 'a frio', em voz alta; (p. 142)

Uma transcriação só difere de um original pela presença, por assim dizer, de um esquema prévio, que determina a forma do texto, tal como na escultura o molde determina a forma do metal. / 0 poeta [...] quando transcria, escreve sobre vidro, copia o poema que está por baixo. [...] Só uma transparência total possibilita a transmutação dos silêncios de uma lingua para outra. (p. 143)

Pese embora a diferença que $A B$ pretende estabelecer entre transcriador e mero tradutor - o primeiro "possuido e dominado [...] pela sua própria língua" (a de chegada), o segundo "dominado pela língua alheia" (p. 142) e arriscandose a corresponder à divulgada definição do traduttore traditore -, tudo o que escreve sobre transcriação - a obrigação de "usar o fôlego e a voz, e o corpo todo feito uma caixa de ressonância", de se usar "a si próprio tal como o actor num palco" (p. 142), bem como a "transparência" (acima citada) que implica respeito pelo original -, tudo isto creio ser obrigação não de um mero tradutor mas de um bom tradutor e verdadeiramente indispensável a um bom tradutor de texto de teatro.

Não me ocuparei aqui das Notas de dicção (orientações para os actores) nem da Bibliografia (um tanto desactualizada, nomeadamente no que se refere a estudos de tradução, com a excepção de Georges Mounin, Les Problèmes théoriques de la traduction), pois se me afiguram complementos de importância relativa em relação ao essencial deste objecto. E quanto a este - a tradução (assim Ihe chamarei sempre daqui em diante) da Phèdre de Racine em versos dodecassílabos brancos portugueses -, justifica o autor a sua rejeição do alexandrino e da rima com as lições de Cândido Lusitano e João Penha, por razões fundamentadas e que têm a ver, principalmente, quer com a difícil adequação daquele metro à língua portuguesa, por questões de sonoridade, quer com a (quase) inevitável distorção que a rima, em português, imporia aos versos de Racine. Contudo, aparece-me bem menos claro aquilo a que AB chama a "monotonia estridente" (p. 145) que resultaria da repetição de alexandrinos. Não porque a estridência (segundo o autor, a do alexandrino) não possa ser monótona mas porque ela nem sempre me parece evitada nos dodecassilabos em que $A B$ traduz esta tragédia, resultando particularmente de rupturas na cadência (na monotonia?), seja pela presença de versos hipermétricos (e alguns hipométricos mas em menor número), seja pela necessidade de tantas soluções de ligação rítmica (elisão, crase, ectlipse, etc.) que a clareza de dicção sai prejudicada, seja ainda por uma distribuição de cesuras e sílabas tónicas dissonante em relação à réplica, cena ou unidade semântica em que o verso se encontra inserido.

\section{Alguns exemplos:}

a) versos hipermétricos: "Quer co'a irmã dos Palântidas enterrar este nome" (108); "Juntai-vos antes às minhas preces bem legítimas" (1181), este facilmente resolúvel com a supressão de bem;

b) versos com excesso de ligações rítmicas: "Desde que a estas margens os Deuses enviaram" (35), obrigando a crase e a diérese (sublinhadas) que tornam menos clara a articulação; "Devido às tuas súplicas esqueci os meus deveres" (v. 1311), elisão e sinalefa que, adicionados aos dois ditongos incluídos no verso (tuas, meus), apressam a dicção, mais uma vez com prejuizo da clareza;

c) versos que rompem a cadência: "Não posso guardar tal dúvida que me oprime" (985), em que toda a acentuação recai sobre o primeiro hemistíquio $\left(1^{\text {a }}, 4^{\mathrm{a}} \mathrm{e}\right.$ 6a sílabas), havendo apenas acentuação da sílaba tónica final no segundo, o que torna o verso não só duro de dizer mas também áspero e chocante no seio da longa réplica de Teseu que dá conta do seu sentimento de perda perante sinais que não sabe interpretar; "Só, digno filho dum herói, ficou Hipólito" (1527), cujas acentuações $\left(1^{\text {a }}, 4^{\text {a }}, 8^{\text {a }}\right.$ e $12^{\text {a }}$ silabas $)$ e cesuras contrastam gritantemente (não será isto estridência?) com as dos que 0 enquadram (rigorosamente divisíveis em dois hemistíquios e acentuados nas 2a $6^{a}, 10^{a}$ e $12^{a}$ sílabas).

Se detalho particularmente estas questões - as de resolução menos feliz na tradução assaz escorreita de $A B$ -, é, por um lado, por aquilo para que procurei chamar a atenção nos meus três primeiros parágrafos - a composição musical da tragédia raciniana - e, por outro, porque o próprio $A B$, como tentei tornar evidente nos parágrafos seguintes, centra a sua reflexão sobre o trabalho feito em diversos aspectos dessa mesma composição, concluindo:

0 mito da música raciniana é sagrado: determina a dicção, aparentemente paradoxal, do discurso no ritmo mais espontaneamente puro da fala humana, em sintonia com a delicadeza mais elaborada pela educação (mistura de linguagem aristocrática com simplicidade familiar, com transições, por vezes, abruptas, a fim de evitar a monotonia de uma elegância obsessiva); e determina o equilibrio entre expressão e técnica, isto é, não se deve transformar o verso em prosa, nem acrescentar-Ihe música, porque o verso já canta por si mesmo e manifesta a sua essência, e as vogais predominantes colaboram neste cântico, que proporciona o sabor. (p. 150)

E sendo certo que tenho dúvidas sobre a "dicção [...] do discurso no ritmo mais espontaneamente puro da fala humana" (tendo em conta a mais recente investigação de restauro da dicção de teatro da época), também é certo que subscrevo o resto da citação, com a ressalva de que as 


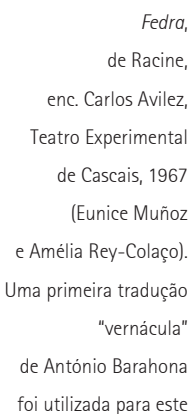

espectáculo.

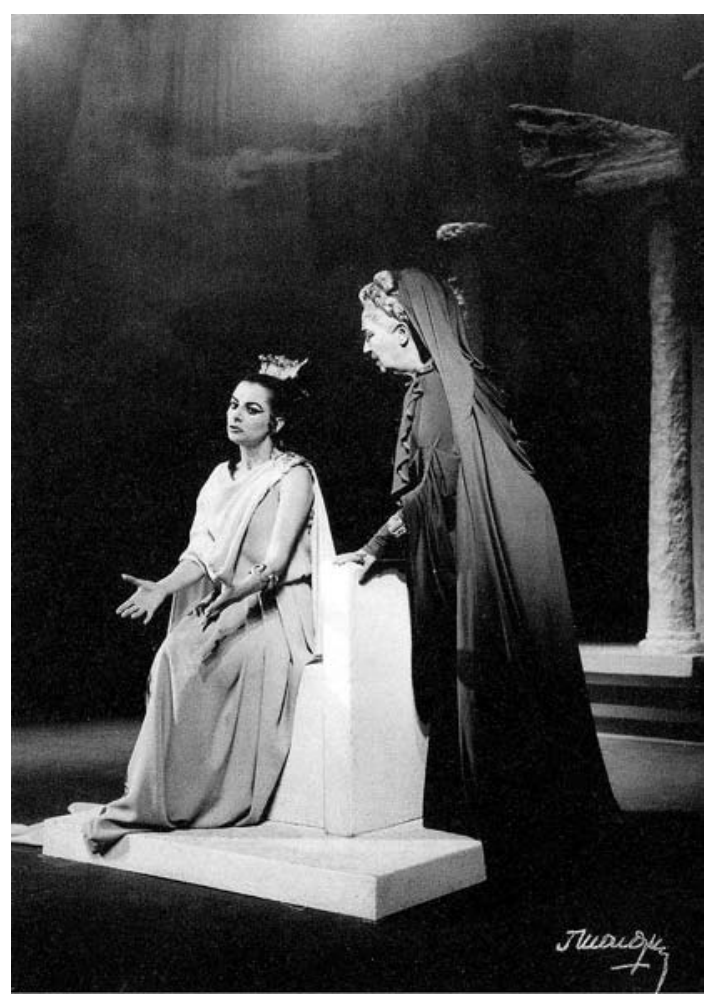

"transições [...] abruptas" não se encontram em Racine ao nivel prosódico e sim ao nível de registos de linguagem e de inflexão de acontecimentos, situações ou sentimentos.

Alguns momentos desta tradução são, na verdade, excelentes e dignos do original. Destes se destacam a terceira réplica de Fedra em I, 3 (vv. 169-172), o início do diálogo entre Arícia e Isméne em II, 1 (sobretudo os vv. 370-376) e a longa réplica de Hipólito em III, 5 (vv. 927-952). Em contrapartida, algumas outras opções são bastante discutiveis, sobretudo por não corresponderem à simplicidade raciniana quer de um ponto de vista de construção frásica quer de clareza de sentido. Assim, em IV, 1, o verso, da réplica de Enone, "Fedra poupava antes a um pai deplorável" (1014), além de uma incorrecção sintáctica (o verbo poupar é transitivo e usa-se sem preposição, esta só serve aqui para que o verso seja isométrico), sofre da tradução literal da palavra francesa déplorable, a qual confere ao verso uma conotação pejorativa que o original não tem. A mesma incorrecção sintáctica (uso inadequado da preposição a) se encontra na primeira réplica de Arícia em V, 1 - "Abandonais no erro a um pai que vos ama?" (v. 1330) -, mais uma vez aparentemente por causa da métrica. Mais gritante é contudo a construção de dois versos da segunda grande réplica de Fedra em IV, 6, a imaginar-se julgada por seu pai, Minos, no inferno - "Quando surgir a filha à frente dos seus olhos,l Confessar, obrigada, inúmeros pecados" (vv.1282-1283) -, erro inverso dos anteriormente apontados (impõe-se aqui o uso da preposição $a$ antes do verbo confessar) mas resolvendo, como os outros, problemas de métrica que poderiam, e deveriam, ser resolvidos de outro modo.

Noutros casos, não se vislumbrando os mesmos motivos (de medida do verso) é maior a estranheza causada. É o caso do final de II, 3, quando Hipólito se despede de Arícia, após Fedra se ter feito anunciar: os versos do original francês "Cependant vous sortez, et je pars et j'ignore/ Si je n'offense point les charmes que j'adore" - que foram transformados por AB em "Agora, saí. Vou partir. E ignorante/ De vos ter ofendido os encantos que adoro!" (vv. 569-570), convertendo em ordem, pelo imperativo (pouco adequado ao carácter de Hipólito) o que era comprovação, no presente (Arícia apresta-se a sair, ao ouvir anunciar Fedra), e afirmando uma ignorância de ofensa que o condicional francês modalizava. Dificilmente se percebe também porque é que "un monstre effroyable à mes yeux" é traduzido por "um monstro, horrivel e doente" (v. 884). Porém o que me merece maiores reparos é a tradução dos últimos quatro versos do Acto III. A réplica de Hipólito termina assim em francês: "Allons, cherchons ailleurs par quelle heureuse adresse/ Je pourrai de mon père émouvoir la tendresse,/ Et lui dire un amour qu'il peut vouloir troubler/ Mais que tout son pouvoir ne saurait ébranlerm. $A B$ traduz como se segue: "Vamos: algures busquemos que sagacidade/ Logrará, a meu pai, despertar a ternura;/ Saberá dum amor, que perturbar bem pode,/ Mas todo o seu poder não torna menos firme" (vv. 997-1000). Como perceber, nesta tradução em que o sujeito eu (Hipólito) é substituido por sagacidade (de quem? Em francês percebe-se) que é Hipólito quem pretende despertar a ternura do pai para o tornar favorável ao seu amor por Aricia? Além de inutilmente complicados, a falta de clareza destes versos dificilmente permite compreender a sua relação com os versos 11291130: "Há seis meses, Senhor, que eu a evito e a amo./ Vinha agora, tremendo a vós próprio dizê-lo".

Em epigrafe ao Posfácio, cita AB Jean-Louis Barrault, o qual compara Fedra a um lustre: "Formoso objecto cintilante,/ cristalino,/ complicado/ circular e/ simétrico" (p. 140). No adjectivo complicado reside o motivo da minha discordância (com Barrault, com AB): Fedra deve ser traduzida em frases simples, com palavras simples; $e_{\text {, }}$ respeitando, tanto quanto possivel, as estruturas rítmicas do verso de Racine. De um modo geral, a tradução de $A B$ corresponde a estes imperativos, mas algumas passagens menos cuidadas ou inutilmente complicadas desfiguram, por momentos, a cintilação e a transparência de tão cristalino objecto. 